\title{
Capacity demands of automatic processes in semantic priming
}

\author{
AVISHAI HENIK \\ Ben-Gurion University of the Negev, Beer Sheva, Israel \\ FRANCES J. FRIEDRICH \\ University of Utah, Salt Lake City, Utah \\ and \\ JOSEPH TZELGOV and SARA TRAMER \\ Ben-Gurion University of the Negev, Beer Sheva, Israel
}

\begin{abstract}
In three experiments, we examined the effects of prime-target stimulus onset asynchrony (SOA) and the proportion of related primes and targets (relatedness proportion, or RP) on semantic priming when the prime was either named or was searched for a specific letter. In Experiment 1, with an RP of .50, priming occurred at SOAs of 240 and $840 \mathrm{msec}$ when the prime was named, but no priming was found at either SOA when the prime was searched for a letter. In Experiment 2 the RP was either .20 or .80 , and the SOA was set at $1,700 \mathrm{msec}$; priming again was found in both conditions when the prime was named, but only in the RP.80 condition when a letter search task was performed on the prime. In Experiment 3, both the proportion of related trials and SOA were varied; as in the previous experiments, no priming effects were found with the letter search task for either SOA in the RP.20 condition, but the priming effect was reinstated in the RP.80 condition. These results are discussed with respect to how limited capacity resources are allocated and how they influence semantic priming effects.
\end{abstract}

The semantic priming effect, in which word recognition is facilitated by a semantically related context, has been widely studied in order to better understand memory organization and word recognition processes (Meyer \& Schvaneveldt, 1971, 1976; Neely, 1977, 1991; Smith, 1979). Several mechanisms have been proposed to account for priming effects, including automatic spreading activation, attentional or expectancy-based processes, and postlexical mechanisms such as a semantic-matching process (see Neely, 1991, for an extensive review). At this point, there is no single mechanism sufficient to account for all of the factors that affect semantic priming, including time course (stimulus onset asynchrony, or SOA), proportion of related trials within the stimulus list (relatedness proportion, or RP), and word-nonword ratios. Indeed, Neely (1991) has suggested that all three types of mechanisms may contribute to priming effects.

One finding that all of these mechanisms must take into account is that of the prime task effect, in which the na-

This research was supported by Grant $84-00050$ from the U.S.-Israel Binational Science Foundation (BSF), Jerusalem, Israel, to the first three authors. We would like to thank Bill Johnston for his helpful comments on an earlier version of this paper. Reprint requests should be sent to A. Henik, Department of Behavioral Sciences, Ben-Gurion University of the Negev, P.O. Box 653, Beer-sheva, Israel 84105 .

-Accepted by previous editor, Margaret Jean Intons-Peterson ture of the task performed on the prime word determines whether semantic priming occurs (Friedrich, Henik, \& Tzelgov, 1991; Henik, Friedrich, \& Kellogg, 1983; Smith, 1979; Smith, Theodor, \& Franklin, 1983). The present experiments were designed to explore the nature of prime task effects in more detail; in particular, the goal was to investigate the prime task effect under conditions that can, in principle, separate the contributions of the automatic spreading activation and the expectancy mechanisms.

The distinction between the automatic and expectancy mechanisms dates back to the earliest studies of semantic priming. The notion of automatic spreading activation is based on the assumption that memory is organized as a complex network of interconnected nodes, and that activation of a concept causes a spread of activation to related concepts in the memory system (Collins \& Loftus, 1975; Posner \& Snyder, 1975a, 1975b). Thus, the semantic priming, or relatedness, effect has been explained as a larger or more reliable spread of activation for concepts that are semantically related than for those that are not. It is believed that this process is automatic in the sense that it occurs rapidly, does not require resources available to the limited-capacity attentional system, and does not depend on conscious awareness or subjects' intentions (Dagenbach, Carr, \& Wilhelmsen, 1989; Fischler, 1977; Marcel, 1983; Neely, 1977; Posner \& Snyder, 1975a).

A nonautomatic, or expectancy-based, process has also been identified. It is assumed that this mechanism oper- 
ates by directing attention to a specific area in memory or by generating a set of expected targets related to the prime word (Becker, 1980; Johnston \& Dark, 1982, 1985; Neely, 1977; Posner \& Snyder, 1975a, 1975b; Tweedy \& Lapinski, 1981). This process occurs more slowly than automatic spreading activation, but is nevertheless assumed to be prelexical in nature; that is, this attentional process produces priming effects by speeding the retrieval of the target word.

Two factors have been especially useful in distinguishing the contributions of spreading activation and expectancy processes to semantic priming. First, it appears that RP influences the expectations of the subject and affects the resulting patterns of facilitation and inhibition (den Heyer, Briand, \& Dannenbring, 1983; Tweedy, Lapinski, \& Schvaneveldt, 1977). A purely automatic process should not be influenced by the characteristics of the stimulus list. Second, Neely (1977) demonstrated that the time courses of the two processes can be charted separately by varying the SOA. Similarly, Posner (1978) suggested that the involvement of attentional mechanisms in the relatedness effect is heavily dependent upon time variables. When the SOA is short (usually $400 \mathrm{msec}$ or less), there is not enough time to commit the central processor to the prime, and performance may reflect only a fast automatic component (den Heyer et al., 1983; McKoon \& Ratcliff, 1986; Neely, 1977). When the SOA is long enough (500 msec or more), the limited resources may be committed to the prime word, and thus performance may reflect attentional factors as well as a residual automatic component.

In many of the priming experiments in which automatic and attentional mechanisms have been investigated, no response to the prime word has been required. However, in recent experiments in which there were attempts to control the nature of prime processing, results have shown that the way in which the prime is processed may influence the relatedness effect. When subjects were asked to search the prime for a letter, the RT difference between related and unrelated priming conditions was essentially eliminated (Besner, Smith, \& McLeod, 1990; Friedrich et al., 1991; Henik et al., 1983; Hoffman \& MacMillan, 1985; Smith, 1979; Smith et al., 1983). ${ }^{1}$ Henik et al. (1983) suggested that when the prime is searched for a letter, attention is drawn to the letter level and, as a result, little or no attention is committed to the lexical level of the prime (see also Greenberg \& Vellutino, 1988). This interpretation is what would be expected, given the long SOA that was used in those studies. A relatively long interval should allow enough time for attention to be committed to the prime in a selective manner.

The present report is a detailed investigation of the use of attentional resources in semantic priming and how such resources are allocated. In the first experiment, we attempted to determine whether the nature of the prime task (e.g., naming vs. letter search) influences the priming effect even at short SOAs, when priming is thought to occur automatically and without intentional allocation of attentional resources. The results have implications for the definition of automaticity. The second experiment was an examination of whether the allocation of resources can be influenced under letter search conditions by manipulating the salience of the semantic relationship. In this case, RP was varied under different prime task conditions in order to determine whether the relatedness effect could be reinstated in the letter search condition with a sufficiently strong semantic context. In the third experiment, both RP and SOA were varied under the two prime task conditions in order to clarify how these factors interact.

\section{EXPERIMENT 1}

As suggested earlier, the SOA, or the interval between the onset of the prime and the onset of the target, is thought to affect the involvement of an attentional mechanism. Posner (1978) suggested that it takes time to commit the central processor to the prime; thus, with short SOAs, activation will spread to concepts related to the prime, with no intention or effort on the part of the subject. If it is assumed that the subject shifts attention to the letter level and away from semantic processing of the prime in the letter search task, then it should be possible to influence the emergence of a priming effect via the manipulation of the SOA. In fact, Hoffman and MacMillan (1985) have suggested that short prime-target intervals are crucial in order to elicit the semantic relatedness effect under prime task conditions such as letter search. Therefore, if we employ a short SOA, we may observe a relatedness effect due to fast automatic processes even when the prime is probed for one of its letters.

There is an alternative possibility, however: It is possible that the essential strategy for allocating attention in such tasks is worked out in advance. In the usual priming situation, the default value for allocation of attention appears to be the semantic level of the prime. When some other task is performed on the prime, attention may be committed to another level (e.g., the letter level) in advance, and no priming effect will appear. Note that this suggestion differs from the idea that the automatic effects observed at short SOAs can occur without attentional resources. If no priming effect occurs with a very short SOA, some attentional resources would appear to be needed, even for the automatic component of the task. Such a suggestion is in line with several recent studies showing that putative automatic processes are influenced by the availability of processing resources (Kahneman \& Henik, 1981; Kahneman, Treisman, \& Burkell, 1983).

In Experiment 1, two prime-target SOAs were employed. In one condition we used a 240-msec SOA, which has been shown to be too short for the intentional commitment of the central processor to influence the semantic priming effect (Neely, 1977). In the other condition we used an SOA of $840 \mathrm{msec}$, for which clear attentional effects have been found (Neely, 1977; Posner, 1978).

\section{Method}

Subjects. Sixteen undergraduate students at Ben-Gurion University of the Negev participated in the experiment in partial fulfillment of a course requirement. All reported normal or correctedto-normal vision. 
Materials. All stimulus materials were in Hebrew; comparable examples in English will be provided here for clarity. Each trial consisted of a prime word and a target string of letters. A prime was always a single word with a probe letter above it. In order to avoid any positional bias, the probe letter appeared above every letter in the prime word, as shown below.

\section{BBBBB}

\section{TABLE}

On half of the trials the probe letter occurred in the prime word and on half it did not. For positive trials, the probe letter was drawn equally often from the beginning, middle, and end of the prime word.

There were three kinds of stimulus pairs: related words, unrelated words, and word-nonword pairs. Twenty-eight related pairs were chosen from Breznitz's (1971) association norms for Hebrew; they consisted of the stimulus and its strongest associate. The unrelated pairs were constructed by re-pairing the targets and the primes. Thus, each pair occurred twice within the list. Pronounceable nonwords were created by scrambling the letters of the target words. The word-nonword pairs were created by using these nonwords once with their "related" primes and once with their "unrelated" primes.

The stimuli were typed in black on white cards. Each string of letters (prime or target) was centered $5 \mathrm{~mm}$ above the center of the card. The vertical distance between the prime and its probe letter string was also $5 \mathrm{~mm}$. Each letter appeared within an $8 \times 8 \mathrm{~mm}$ square with an intersquare space of $3 \mathrm{~mm}$. These words consisted of three, four, or five letters. The subjects sat $80 \mathrm{~cm}$ from the screen. A four-letter word, therefore, subtended approximately $2.93^{\circ}$ of visual angle.

Apparatus. The stimuli were presented with a Harvard threefield tachistoscope. A Monsanto counter-timer was used to measure reaction times to the nearest millisecond.

Design. Overall, the stimulus list consisted of 112 experimenta stimulus pairs; the same list was presented in each session. Half of the targets were words and half were nonwords. Half of the wordword pairs (28) were related and half were unrelated. Within each relatedness condition, half of the pairs (14) were presented in the short-SOA condition, and the rest were presented in the long-SOA condition. Within each subgroup of 14 pairs, 7 were positive trials (with respect to the presence of the probe letter in the prime word) and 7 were negative. Short and long SOAs were randomly intermixed within a session; however, the 56 pairs employed in the shortSOA condition in one session were presented in the long-SOA condition in the other session, and vice versa. Thus, each stimulus pair was presented twice across sessions, once in each SOA condition.

Procedure. Each subject participated in two sessions and had received practice prior to each set of test trials. In one session the subjects performed a naming task on the prime word, and in the other they searched the prime for the probe letter. In all cases they performed a lexical decision on the target. Half of the subjects performed the naming task on their first session and the other half on their second session. On every trial the prime was presented for $140 \mathrm{msec}$. The targets were presented either 240 or $840 \mathrm{msec}$ from the onset of the prime and remained in view until the subject pressed one of two keys to indicate a word/nonword decision. Because of the short-SOA trials, the subjects were asked to respond orally to the prime (yes/no for the letter search, or reading the prime aloud for the naming task) only after their responses to the target. Consequently, the sequence of responses on a trial was as follows: the subject made no overt response upon prime exposure, responded with a keypress to indicate a lexical decision for the target, and only then responded orally to the prime. Responses to the primes were recorded by the experimenter.
Table 1

Mean Lexical Decision RTs (in Milliseconds) and Percentage of Errors for Experiment 1

\begin{tabular}{|c|c|c|c|c|c|c|}
\hline \multirow[b]{3}{*}{ Prime Task } & \multicolumn{4}{|c|}{ Condition } & \multirow{2}{*}{\multicolumn{2}{|c|}{$\begin{array}{c}\text { Priming } \\
\text { Effect }\end{array}$}} \\
\hline & \multicolumn{2}{|c|}{ Related } & \multicolumn{2}{|c|}{ Unrelated } & & \\
\hline & $\bar{M}$ & $\%$ & $M$ & $\%$ & $\mathrm{RT}$ & $\%$ \\
\hline \multicolumn{7}{|l|}{ Naming } \\
\hline Short SOA & 723 & 2.2 & 773 & 3.5 & +50 & 1.3 \\
\hline Long SOA & 694 & 1.3 & 737 & 3.9 & +43 & 2.6 \\
\hline \multicolumn{7}{|l|}{ Search } \\
\hline Short SOA & 1,008 & 1.8 & 983 & 5.3 & -25 & 3.5 \\
\hline Long SOA & 778 & 2.6 & 785 & 1.3 & +7 & -1.3 \\
\hline
\end{tabular}

\section{Results}

For each subject, a median lexical decision RT (reaction time) for correct word responses was calculated for each condition. Group means for RTs and percentages of lexical decision errors are presented in Table 1.

The lexical decision RTs were submitted to a four-way mixed analysis of variance (ANOVA) to evaluate the effects of the between-subjects factor of task order and the within-subject factors of SOA, prime task, and relatedness. Lexical decisions on the targets were faster when the prime was named than when it was searched for a letter $\left[F(1,14)=29.76, M S_{\mathrm{e}}=26,415, p<.001\right]$, and were faster when the SOA was long than when it was short $\left[F(1,14)=15.52, M S_{\mathrm{e}}=31,575, p<.001\right]$. However, these two effects also produced a significant interaction $\left[F(1,14)=16.12, M S_{\mathrm{e}}=16,381 p<.001\right]$. In addition, the task $\times$ relatedness interaction was significant $\left[F(1,14)=5.44, M S_{\mathrm{e}}=4,618, p<.05\right]$. No other effects reached significance.

In order to clarify the factors contributing to these twoway interactions, we carried out additional comparisons for each interaction. The analysis of the task $\times$ SOA interaction revealed that, in the letter search condition, the lexical decision RTs were significantly faster for the longSOA than for the short-SOA trials $[F(1,15)=26.05$, $M S_{\mathrm{e}}=28,275, p<.001$ ]; in the naming condition, however, there was no reliable difference between the SOA conditions $(F<1)$. The relatedness $\times$ task interaction was due to a significant relatedness effect when the primes were named $\left[F(1,15)=22.20, M S_{\mathrm{e}}=1,708, p<.001\right]$, but not when they were searched for a letter $(F<1)$. Thus, we found no evidence in the RT data of a priming effect for either the short or long SOA when a letter search was performed on the prime word.

To determine whether the subjects in the letter search conditions were actually showing small but nonsignificant relatedness effects, we also looked at the pattern of results for individual subjects. In the naming task, 13 of the 16 subjects in each SOA condition showed a relatedness effect; the rest showed the reverse pattern. In contrast, when the prime task involved letter search, only 5 subjects in the short-SOA condition and 9 subjects in the long-SOA condition showed a relatedness effect pattern. 
The lexical decision error rate was low, with a mean error rate of $2.73 \%$ overall. Errors were analyzed in a four-way ANOVA that included task order as the betweensubjects variable and SOA, prime task, and relatedness as within-subject variables. The results showed significant main effects of task order $\left[F(1,14)=5.61, M S_{\mathrm{e}}=\right.$ $46.16, p<.05]$ and relatedness $\left[F(1,14)=11.07, M S_{\mathrm{c}}=\right.$ $6.78, p<.005]$. Overall, the lexical decision error rate was higher for the subjects who performed the letter search task in the first session than for those who performed the naming task first, and error rates were higher in the unrelated than in the related conditions. No higher order interactions reached significance.

One concern in the interpretation of these error data is that the error rates were low; in many cases, the average rate was equivalent to less than one error per subject per condition. Therefore, we looked at the consistency of the error data across subjects. The individual-subject data show that relatedness effects in accuracy (i.e., more errors in the unrelated than in the related condition) were limited to a small subset of the subjects. When the prime task was naming, under the short-SOA condition, 4 subjects showed a relatedness effect, 3 showed the reverse pattern, and 9 showed no difference; for the long-SOA condition, 6 subjects showed a relatedness effect, 1 showed the reverse pattern, and 9 showed no difference. The condition in which the accuracy relatedness effect appears to be the largest is in the short-SOA search task condition, and even in that case only 7 subjects produced a relatedness effect pattern in accuracy, with 3 subjects showing the reverse and 6 showing no difference. In fact, the difference between the means of the related and unrelated conditions is due primarily to 1 subject, who made twice as many errors as any other subject in the unrelated condition. Finally, in the long-SOA search condition, only 1 subject showed a relatedness pattern in errors, 4 showed the reverse, and 11 showed no difference.

\section{Discussion}

In general, the RT analysis replicates previous findings (Friedrich et al., 1991; Henik et al., 1983; Hoffman \& MacMillan, 1985; Smith, 1979; Smith et al., 1983) showing that a relatedness effect occurs when the prime word is named, but does not occur when the prime is probed for one of its letters. Rather long prime-target intervals were used in those studies, however, so any evidence of priming in the short-SOA condition is of particular interest in the present experiment. The RT data show quite clearly that priming does not occur at short SOAs, with a priming effect of $-25 \mathrm{msec}$; in the long-SOA condition, the related-unrelated difference was a nonsignificant +7 msec.

Hoffman and MacMillan (1985) have argued that error rates may reveal priming effects even when RTs do not. Indeed, there is some evidence in the present experiment of a relatedness effect in the error analysis, which showed a main effect of relatedness that is not qualified by prime task or SOA. The largest difference in related and unrelated error rates (3.5\%) occurred in the most critical condition-the short-SOA letter search condition-a finding that stands in contradiction to the -25 -msec priming effect found in the RT data. However, even these error data do not constitute very strong evidence that priming occurred in the short-SOA condition, because the effect seems to be limited to a small number of subjects; only 7 produced an error pattern consistent with a relatedness effect.

Accepting the RT data at face value, a strong interpretation of these results would be that even under very short SOAs, before attentional mechanisms have had time to operate, the resource demands of the prime task can effectively eliminate spreading activation. The implication is that there are clear resource requirements in the rapid automatic component of the semantic priming mechanism. It is difficult to make such a strong claim, however, because the RTs in the short-SOA letter search condition were considerably longer than in any other condition. These long RTs may suggest that the subjects still attempted to carry out the search task when the target appeared. (Note, however, that the actual response to the prime was not made until after the lexical decision task was performed on the target.) Although this finding is encouraging to the extent that it indicates that the subjects were following instructions in how to attend to the prime word, it also may mean that the prime-target SOA was increased functionally. That is, even though the target was presented $240 \mathrm{msec}$ after the prime word, the subjects may not have begun to process the target until some time later, when the automatic activation may have already decayed.

In order to make a convincing case that priming does not occur under letter search conditions at short SOAs, therefore, it seemed important to try to reduce the lexical decision RTs in the short-SOA condition. In a series of pilot studies, we made a number of modifications of this paradigm in order to do so. For example, in Experiment 1 the two SOAs were mixed within a session; in a pilot study the SOAs were blocked but, unfortunately, the RTs in the short-SOA condition remained unusually long. Attempts to precue the letter probe were also unsuccessful in reducing the RTs in that condition. As far as these efforts were concerned, using this letter search paradigm resulted in longer RTs in short-SOA conditions, even when the prime task response was delayed until after the lexical decision response. Thus, the question of whether priming can be eliminated at short SOAs remains unanswered from the results of the first experiment. We will return to this issue in Experiment 3.

\section{EXPERIMENT 2}

Although semantic priming has been shown in the past to result from either fast "automatic" or slower "intentional" processes, the results from Experiment 1 suggest that neither process will produce priming under the letter search condition. In the letter search condition, attentional resources must be committed to the prime in order to carry 
out the prime task, but they are devoted to the level of letter analysis rather than to semantic processing. If there is any activation of the semantic network from an initial rapid automatic process, it does not appear to be strong enough to persist when resources are committed to the letter search task.

An important question remains: Can expectancy processes be manipulated in the letter search condition so that significant resources are committed to semantic processes in order to produce a priming effect? If the semantic level is made salient so that some attentional resources are focused on the semantic relationship between the prime and the target, will that compensate for the effects of the letterlevel analysis?

One variable that has been shown to be quite effective in affecting subjects' expectations and attentional processes is RP, which has been shown to influence the size of the priming effect (Koriat, 1981; Tweedy \& Lapinski, 1981; Tweedy et al., 1977). For example, if $80 \%$ of the trials are related (and 20\% are unrelated), the relatedness effect is larger than when only $20 \%$ of the trials are related (den Heyer et al., 1983; Neely, 1977; Posner, 1978). Consequently, these results are thought to reflect an active commitment of attertional resources to the prime.

In Experiment 2, we attempted to manipulate attention by varying the RP under long-SOA conditions. One group of subjects was tested with a list of word pairs that contained $80 \%$ related trials and $20 \%$ unrelated trials (RP. 80 condition), and another group of subjects received a list of pairs that contained $20 \%$ related trials and $80 \%$ unrelated trials (RP.20 condition). Each group performed a naming task on the prime in one session and a letter search task in the other session. The major question was whether it was possible to influence the amount of activation occurring at the semantic level, even when a letter search task was being carried out. If this is possible, then we would expect to observe a relatedness effect under letter search conditions in the RP. 80 condition, but little or no effect in the RP.20 condition.

\section{Method}

Subjects. Forty-eight undergraduate students participated in the experiment in partial fulfillment of course requirements. All reported normal or corrected-to-normal vision; none had participated in the previous experiment.

Materials. As in Experiment 1, each trial consisted of a prime word (with letters above it) and a target. The total number of stimuli in the present experiment was larger than in Experiment 1 because of the need for filler items and because each prime and target were presented only once in each session. However, the number of critical trials analyzed was comparable to that of Experiment 1.

There were two stimulus lists. Each consisted of 240 pairs-half were word-nonword pairs and half were word-word pairs. At the outset, each list of 120 word-word pairs was composed of related pairs; of these, 24 pairs were re-paired and served as unrelated, 24 served as related, and 72 as fillers. In the RP. 80 condition the 72 fillers were used in their original (related) form, and in the RP. 20 condition they were re-paired in order to create unrelated pairs.

Each subject received the same list of stimuli in both the letter search and the naming sessions. The order of presentation of the 240 trials within each list was changed from session to session. The related and unrelated conditions, for each subject, were composed of different pairs of words, so that for a given subject a target word occurred in only one condition in each session. However, across subjects, each of the 48 analyzed targets ( 24 from the related trials and 24 from the unrelated trials) appeared equally often in each of the prime task conditions and in the related and unrelated conditions.

Apparatus. Stimulus presentation and data collection were controlled by an Apple IIe. The stimuli were presented on a television screen that was at eye level, approximately $50 \mathrm{~cm}$ from the subject. On this screen each letter was $6 \mathrm{~mm}$ high and $5 \mathrm{~mm}$ wide, and the distance between two adjacent letters was $2 \mathrm{~mm}$. The vertical distance between the line of probe letters and the prime was $2 \mathrm{~mm}$. The visual angle subtended by a four-letter word was approximately $2.96^{\circ}$

Procedure. Twenty-four subjects were tested in the $80 \%$ related condition and 24 in the $20 \%$ related condition. In each group, 12 subjects received one list of stimuli and 12 received the other list. All the subjects participated in two sessions-in one, naming was the prime task; in the other, letter search was the prime task. Task order was counterbalanced across subjects.

On each trial, the prime appeared for $1 \mathrm{sec}$ and was followed by a blank interval of $700 \mathrm{msec}$ prior to the target presentation, as in our earlier studies (Henik et al., 1983). The subjects made the prime word response (vocally) prior to target presentation. In all other respects, the design and procedure were similar to those of the previous experiment.

\section{Results and Discussion}

As in the previous experiment, a median lexical decision RT for correct word responses was calculated for each condition and each subject. Group means for RTs and percentages of lexical decision errors are presented in Table 2.

A four-way mixed ANOVA showed significant main effects of prime task, with faster RTs when the prime task was naming than when it was letter search $[F(1,44)=$ $\left.6.08, M S_{\mathrm{e}}=14,785, p<.025\right]$. There were also significant main effects of relatedness, with faster RTs for related trials than for unrelated trials $[F(1,44)=67.03$, $\left.M S_{\mathrm{e}}=2,256, p<.001\right]$. However, the two-way interactions of task $\times$ relatedness and proportion $\times$ relatedness were also significant $\left[F(1,44)=9.22, M S_{\mathrm{e}}=2,333\right.$, $p<.005$, and $F(1,44)=10.02, M S_{\mathrm{e}}=2,256, p<$ .005 , respectively], as was the three-way interaction of

Table 2

Mean Lexical Decision RTs (in Milliseconds) and Percentage of Errors for Experiment 2

\begin{tabular}{|c|c|c|c|c|c|c|}
\hline \multirow{3}{*}{$\begin{array}{l}\text { Prime } \\
\text { Task }\end{array}$} & \multicolumn{4}{|c|}{ Condition } & \multirow{2}{*}{\multicolumn{2}{|c|}{$\begin{array}{c}\text { Priming } \\
\text { Effect }\end{array}$}} \\
\hline & \multicolumn{2}{|c|}{ Related } & \multicolumn{2}{|c|}{ Unrelated } & & \\
\hline & $M$ & $\%$ & $M$ & $\%$ & $\mathrm{RT}$ & $\%$ \\
\hline \multicolumn{7}{|l|}{ Naming } \\
\hline RP.20 & 602 & 0.9 & 643 & 3.0 & +41 & 2.1 \\
\hline RP. 80 & 541 & 0.6 & 655 & 7.9 & +114 & 7.3 \\
\hline \multicolumn{7}{|l|}{ Search } \\
\hline RP. 20 & 683 & 1.4 & 712 & 2.4 & +29 & 1.0 \\
\hline RP. 20* & 666 & 1.5 & 674 & 2.5 & +8 & 1.0 \\
\hline RP.80 & 589 & 0.6 & 631 & 4.4 & +42 & 3.8 \\
\hline RP. $80^{*}$ & 592 & 0.7 & 628 & 4.4 & +36 & 3.7 \\
\hline
\end{tabular}

*Means calculated excluding 1 subject in each condition. See text for explanation. 
task $\times$ relatedness $\times$ proportion $\left[F(1,44)=4.62, M S_{\mathrm{e}}=\right.$ $2,333, p<.05]$. In addition, the order of prime tasks interacted with task $\left[F(1,44)=13.76, M S_{\mathrm{e}}=14,785\right.$, $p<.001]$ and with proportion $\left[F(1,44)=12.15, M S_{\mathrm{e}}\right.$ $=45,688, p<.001]$.

The result of primary importance was the three-way interaction of task $\times$ relatedness $\times$ proportion, which essentially shows that the effects of the prime task can be moderated by the salience of the semantic relationships within the stimulus list. Analyses of simple interaction effects showed that when the primes were named, there were significant relatedness effects in both the RP. 80 $\left[F(1,23)=131.84, M S_{\mathrm{e}}=1,182, p<.001\right]$ and the RP. 20 conditions $\left[F(1,23)=14.91, M S_{\mathrm{e}}=1,328, p<\right.$ $.001 \mathrm{~J}$. In contrast, when the primes were searched for letters, there was a significant relatedness effect in the RP.80 condition $\left[F(1,23)=15.45, M S_{\mathrm{e}}=1,350, p<.001\right]$, but not in the RP. 20 condition $\left[F(1,23)=1.77, M S_{\mathrm{e}}=\right.$ $5,406, p>.15]$. Thus, it appears that if the semantic relationships within the stimulus list are made salient, the priming effect can be reinstated even under letter search conditions.

As in the previous experiment, we examined the data from individual subjects in order to get a sense of how consistent this effect was across individuals. When the primes were named, 23 of the subjects showed a relatedness effect in the RP. 80 condition and 20 subjects showed a relatedness effect in the RP. 20 condition. For the letter search task, 19 subjects showed a relatedness effect in the RP.80 condition, whereas 15 showed priming in the RP. 20 condition.

Although the simple interaction effects showed that the priming effect in the RP. 20 letter search task was not significant, the size of the effect ( 29 msec) was considerably larger than we have found in previous studies when using the letter search task. Inspection of the data revealed that the size of this effect was due almost entirely to 1 subject, who exhibited a 477-msec relatedness effect. This effect is twice as large as the largest priming effect in the entire experiment (even in the naming RP.80, which was most favorable for priming). It is, of course, beyond the range of the size of priming effects in its own condition $(-85$ to $+74 \mathrm{msec})$ or in the RP.80 letter search condition $(-50$ to $+160 \mathrm{msec})$. If the data of this subject are not included in the group means, the average relatedness effect in the letter search RP. 20 condition drops from 29 to $8 \mathrm{msec}$, which is consistent with previous findings.

We performed an additional ANOVA on the letter search data only, excluding the data of this subject. We also excluded the data of the subject with the largest relatedness effect (i.e., $160 \mathrm{msec}$ ) in the RP.80 condition. (Note that this procedure was very conservative. Although none of the subjects were even close to the $477-$ msec effect, there were quite a few in the letter search $80 / 20$ condition with effects close to $160 \mathrm{msec}$; in fact, the next largest effect was $150 \mathrm{msec}$.) We performed a two-way (proportion $x$ relatedness) ANOVA to test for an interaction between the two factors. The results were consistent with the origi- nal analysis, showing a significant interaction of proportion $\times$ relatedness, as expected $\left[F(1,44)=4.59, M S_{\mathrm{e}}=\right.$ $970, p<.05$ ]. The exclusion of the 2 subjects resulted in a nonsignificant 8-msec relatedness effect in the letter search RP. 20 condition and a significant $36-\mathrm{msec}$ relatedness effect in the letter search RP.80 condition.

Finally, two task order interactions were significant, as mentioned earlier. Basically, the task order $\times$ prime task interaction reflects the effects of practice. Lexical decision response times were slower in the first task than in the second; however, this difference was larger when the primes were searched for letters in the first session (for search, $M=711 \mathrm{msec}$; for naming, $M=602 \mathrm{msec}$ ) than when they were named in the first session (for search, $M=596 \mathrm{msec}$; for naming, $M=618 \mathrm{msec}$ ). The pattern of the task order $\times$ proportion interaction shows that, collapsed over relatedness and prime task, the subjects in the RP. 80 condition who started with the letter search task responded faster $(M=575 \mathrm{msec})$ than those who started with naming $(M=633 \mathrm{msec})$. In contrast, in the RP. 20 condition, the subjects who started with the letter search task were generally much slower $(M=738 \mathrm{msec})$ than those who started with naming $(M=582 \mathrm{msec})$. This pattern suggests that task order and proportion of related trials had a joint effect on absolute response times. In particular, the use of .80 relatedness proportion reduced the RT, even when the subjects received the letter search task in their first session. This pattern, in conjunction with the lack of a relatedness $\times$ prime task $\times$ task order interaction, supports the suggestion that the priming effect in the RP. 80 letter search task was a genuine one that was not related to practice or some general strategic effects.

As in the first experiment, the lexical decision error rate was low, averaging $2.6 \%$ overall. A four-way ANOVA of errors showed significant main effects of proportion $\left[F(1,44)=4.61, M S_{\mathrm{e}}=1.31, p<.05\right]$, task $[F(1,44)=$ $\left.5.03, M S_{\mathrm{e}}=0.50, p<.05\right]$, and relatedness $[F(1,44)=$ $\left.48.83, M S_{\mathrm{e}}=0.79, p<.001\right]$. Overall, more errors occurred in the RP. 80 than in the RP. 20 conditions, more errors occurred in the unrelated than in the related conditions, and more errors occurred in the naming than in the search task conditions. However, proportion also interacted significantly with task $\left[F(1,44)=4.16, M S_{\mathrm{e}}=\right.$ $0.50, p<.05$ ], reflecting more errors in the RP.80 naming condition than in any other. Of particular interest, however, are the interactions between relatedness and proportion $\left[F(1,44)=15.21, M S_{\mathrm{e}}=0.79, p<.001\right]$ and relatedness and task $\left[F(1,44)=10.39, M S_{\mathrm{e}}=0.39, p<\right.$ $.005]$. These effects reflect larger priming effects for accuracy in the RP. 80 than in the RP. 20 conditions, and larger effects in the naming condition than in the search tasks.

Although the error data show a pattern of effects that is consistent with the RT data, it should be noted that in this experiment, as in the previous one, error rates were generally quite low and only $60 \%$ of the subjects showed any differences between conditions, which suggests that the results of these error analyses should be interpreted with caution. Inspection of the data from individual subjects 
showed that when primes were named, 19 of the subjects showed a relatedness effect and 5 showed no difference in the RP. 80 condition. In the RP. 20 condition, 12 subjects showed the effect, 3 showed the reverse pattern, and 9 showed no difference. When the primes were searched for letters, 14 of the subjects showed a relatedness effect and 10 showed no difference in the RP. 80 condition. In the RP. 20 condition, 7 of the subjects showed priming, 2 showed the reverse, and 15 showed no difference.

In summary, then, in Experiment 2 we attempted to manipulate the way that attentional resources were allocated to the prime by changing the proportions of the related and unrelated trials. The significant priming effect achieved when the primes were searched for letters in the RP. 80 condition supports the notion that some activation of the semantic level can be maintained even when analysis must occur at the letter level, if semantic salience is highlighted through this type of manipulation. Note, however, that in the RP. 80 condition, the size of the priming effect in the letter search task is considerably reduced relative to that of the naming task. These findings are in line with the idea that in the letter search task, nodes in the network get some activation, but this activation may decay if there are no resources to maintain it. Thus, the intentional focus of attention through expectations may have its influence in the maintenance of that faint activation that decays over time.

In Experiment 2, the SOA was $1,700 \mathrm{msec}$, thus limiting our interpretation of these findings to a situation in which expectancy mechanisms are assumed to contribute. In Experiment 3, we varied the proportion of related trials in both short- and long-SOA conditions in order to determine how these factors interact with the different prime tasks.

\section{EXPERIMENT 3}

As discussed previously, RP has been shown to influence the size of priming effects at long SOAs, which is consistent with the notion that this factor influences the slow attentional priming mechanism (den Heyer et al., 1983; Neely, 1977). In this context, we would expect that proportion of relatedness should have little effect at short SOAs for either the naming or the search task conditions, because these conditions presumably reflect automatic spreading activation. However, the existing literature is mixed on this point. For example, den Heyer et al. reported that RP affected the size of the semantic priming effect at an SOA of 1,000 msec, but not at a 75-msec SOA (no prime task was performed in their experiments). In contrast, de Groot (1984) found that varying RP affected the size of the priming effect to the same degree at SOAs of 240, 540, and 1,040 msec. Results reported by Snow and Neely (1987), using a rather different paradigm, also suggest RP effects at both short (80 and $200 \mathrm{msec})$ and long $(1,000 \mathrm{msec})$ SOAs. Their stimulus lists included word pairs that were physically identical, nominally identical, or semantically related, and the overall construc- tion of the lists, in terms of the proportion of each word pair type, was varied for different subject groups. Semantic priming was reduced with the proportion of semantically related word pairs at both the short and long SOAs. Therefore, if priming that is based on spreading activation does require some attentional resources, or if $R P$ somehow allows semantic salience to be "set" at the outset of a block of trials, then RP may influence priming at both short and long SOAs

Given this apparent conflict in the existing literature, it was difficult to predict how SOA and proportion of relatedness would interact in the present experiment. However, our previous results do suggest that priming under letter search conditions should be reduced or eliminated at both short and long SOAs in the RP. 20 condition and should be reinstated for long SOAs in the RP. 80 condition.

\section{Method}

Subjects. Forty-eight undergraduate students at Ben-Gurion University of the Negev participated in this experiment in partial fulfillment of a course requirement. All had normal or corrected-to-normal vision, and none had participated in the previous experiments.

Apparatus and Materials. The apparatus and materials were the same as described in Experiment 2; there were 48 critical primetarget word pairs ( 24 related, 24 unrelated) used in the data analyses. The remaining pairs in the stimulus list consisted of word-nonword pairs and word-word filler items, whose characteristics varied for the $80 \%$ related and $20 \%$ related conditions.

Design. The design was the same as in Experiment 2, with the exception that the SOA was included as a within-subject variable. Overall, then, there were two groups of 24 subjects each; one group received the list with $80 \%$ related trials and the other group received the $20 \%$ related list. Each subject participated in both the naming and letter search tasks, in separate sessions; task order was counterbalanced across subjects. Within each session, equal numbers of trials were presented at the short $(240 \mathrm{msec})$ and long $(840 \mathrm{msec})$ SOAs; the SOAs were randomly intermixed within a session. Also within a session, an equal number of word and nonword responses was required.

Procedure. The basic procedure was similar to that of Experiment 1 . Because both short and long SOAs were included, the prime word, with probe letters, was presented for $140 \mathrm{msec}$; the blank interval between the prime and the target was either 100 or $700 \mathrm{msec}$. The subjects made a keypress (word/nonword) response to the target first, followed by a vocal (yes/no or naming) response to the prime word. Responses to the prime word were recorded by the experimenter.

\section{Results}

For each subject, a median lexical decision RT for correct word responses was calculated for each condition. Group means for RTs and percentage of lexical decision errors are presented in Table 3.

A five-way mixed ANOVA included proportion of related trials $(.80 / .20)$ and task order (search first/naming first) as between-subject factors and prime task (naming/ search), relatedness (related/unrelated), and SOA (short/ long) as within-subjects factors. The main effects for prime task, SOA, and relatedness were all significant at $p<.001$ $\left[F(1,44)=62.2, M S_{\mathrm{e}}=61,896 ; F(1,44)=143.5, M S_{\mathrm{e}}=\right.$ 23,453 ; and $F(1,44)=33.5, M S_{\mathrm{e}}=6,528$, respectively]. The main effect of task order was significant at $p<.05$ 
Table 3

\begin{tabular}{|c|c|c|c|c|c|c|c|c|c|c|c|c|}
\hline \multirow[b]{3}{*}{ Task } & \multicolumn{8}{|c|}{ Short SOA } & \multicolumn{4}{|c|}{ Long SOA } \\
\hline & \multicolumn{2}{|c|}{ Related } & \multicolumn{2}{|c|}{ Unrelated } & \multicolumn{2}{|c|}{$\begin{array}{c}\text { Priming } \\
\text { Effect }\end{array}$} & \multicolumn{2}{|c|}{ Related } & \multicolumn{2}{|c|}{ Unrelated } & \multicolumn{2}{|c|}{$\begin{array}{l}\text { Priming } \\
\text { Effect }\end{array}$} \\
\hline & $M$ & $\%$ & $M$ & $\%$ & RT & $\%$ & $M$ & $\%$ & $M$ & $\%$ & RT & $\%$ \\
\hline \multicolumn{13}{|c|}{$20 \%$ Related } \\
\hline Naming & 780 & 4.8 & 772 & 7.2 & -8 & 2.3 & 635 & 1.7 & 655 & 9.4 & 20 & 7.7 \\
\hline Search & 989 & 6.9 & 1,007 & 8.3 & 18 & 1.4 & 758 & 8.0 & 768 & 8.0 & 10 & 0.0 \\
\hline \multicolumn{13}{|c|}{$80 \%$ Related } \\
\hline Naming & 653 & 3.1 & 771 & 8.3 & 118 & 5.2 & 546 & 2.1 & 676 & 9.4 & 120 & 7.3 \\
\hline Search & 1,011 & 4.9 & 1,056 & 8.7 & 45 & 3.8 & 726 & 2.1 & 776 & 5.2 & 50 & 3.1 \\
\hline
\end{tabular}

$\left[F(1,44)=6.1, M S_{\mathrm{e}}=186,688\right]$. These effects reflect faster RTs for the naming than for the letter search task ( $M=686$ and $886 \mathrm{msec}$, respectively), as well as for lettersearch-first than for naming-first task order $(M=732$ and $841 \mathrm{msec}$, respectively), for long than for short SOAs ( $M=692$ and $879 \mathrm{msec}$, respectively), and for related than for unrelated trials $(M=762$ and $810 \mathrm{msec}$, respectively). The main effect of proportion of related trials did not approach significance $(F<1)$, but that factor did interact significantly with relatedness $[F(1,44)=21.2$, $\left.M S_{\mathrm{e}}=6,528, p<.001\right]$. This interaction indicates that, overall, the difference between RTs for related and unrelated pairs was much greater in the RP.80 $(86 \mathrm{msec})$ than in the RP. 20 condition $(10 \mathrm{msec})$.

Two other two-way interactions were also significant. The prime task $\times$ SOA interaction $[F(1,44)=24.0$, $\left.M S_{\mathrm{e}}=20,407, p<.001\right]$ indicates that the RT advantage for long SOAs over short SOAs was greater when the prime task was search than when it was naming. The prime task $\times$ relatedness interaction $\left[F(1,44)=4.6, M S_{\mathrm{e}}\right.$ $=6,167, p<.05]$ reflects a larger priming effect in the naming task than in the search task. However, this latter interaction was further qualified by a significant threeway interaction involving proportion $\times$ prime task $\times$ relatedness $\left[F(1,44)=6.9, M S_{\mathrm{e}}=6,167, p<.05\right]$.

This three-way interaction reflects that, in the RP. 80 condition, there was a large difference in the sizes of the priming effect in the naming $(119 \mathrm{msec})$ and search $(48 \mathrm{msec})$ conditions, but in the RP. 20 condition, the priming effects were small and comparable in size (6 $\mathrm{msec}$ for naming and $14 \mathrm{msec}$ for search). This general pattern was confirmed by separate two-way repeated measures analyses on the RP. 80 and RP. 20 groups. For the RP. 80 group, the sizes of the priming effect in the naming and search tasks were shown to be significantly different, as reflected in the prime task $\times$ relatedness interaction $\left[F(1,23)=13.4, M S_{\mathrm{e}}=\right.$ $5,191, p<.005]$. For the RP.20 group, neither that interaction nor the main effect of relatedness approached significance $(F<1)$.

Inspection of the data from individual subjects showed that, in general, more of the subjects showed a benefit for related (compared with unrelated) trials in the naming than in the letter search tasks. Interestingly, although SOA did not interact with relatedness and prime task in the analyses, a few more subjects showed a benefit in related trials in the long- than in the short-SOA conditions. Within the RP. 80 group in the naming task, 22 and 23 subjects showed a relatedness effect for the short and long SOAs, respectively; the comparable figures for the letter search task were 14 and 16 subjects. When only $20 \%$ of the word-word pairs were semantically related and the prime task was naming, 12 and 15 subjects showed priming in the short- and long-SOA conditions, respectively. In the search condition, 10 and 13 subjects showed priming in the two SOAs. Overall, performance was much more variable for the subjects in the RP. 20 condition.

Finally, the four-way interaction of task order $\times$ prime task $\times$ relatedness $\times$ SOA was also significant $[F(1,44)=$ 4.2, $\left.M S_{\mathrm{e}}=5,526, p<.05\right]$. These data are presented in Table 4. The nature of this interaction was further investigated by conducting separate analyses within each task order group. The subjects who performed naming as the prime task first, followed by a session in which letter search was the prime task, showed main effects of prime task, relatedness, and SOA at $p<.01$, reflecting the same patterns described previously $[F(1,23)=22.8$, $M S_{\mathrm{e}}=71,946 ; F(1,23)=8.9, M S_{\mathrm{e}}=11,829 ;$ and $F(1,23)=83.6, M S_{\mathrm{e}}=26,001$, respectively]. In addition, prime task interacted with SOA $[F(1,23)=17.3$, $M S_{\mathrm{e}}=27,707, p<.001$ ], indicating that the effect of SOA was larger in the letter search than in the naming task condition.

The results of the analysis performed on the data from the subjects who performed the search task first were bas-

Table 4

Mean Lexical Decision RTs (in Milliseconds) in Experiment 3, Including Task Order Factor

\begin{tabular}{|c|c|c|c|c|c|c|}
\hline \multirow[b]{2}{*}{ Task } & \multicolumn{3}{|c|}{ Short SOA } & \multicolumn{3}{|c|}{ Long SOA } \\
\hline & Related & Unrelated & $\begin{array}{l}\text { Priming } \\
\text { Effect }\end{array}$ & Related & Unrelated & $\begin{array}{l}\text { Priming } \\
\text { Effect }\end{array}$ \\
\hline \multicolumn{7}{|c|}{ Search First } \\
\hline Naming & 656 & 710 & 54 & 520 & 608 & 88 \\
\hline Search & 916 & 968 & 52 & 737 & 738 & 1 \\
\hline \multicolumn{7}{|c|}{ Naming First } \\
\hline Naming & 777 & 833 & 56 & 661 & 723 & 62 \\
\hline Search & 1,084 & 1,095 & 11 & 747 & 806 & 59 \\
\hline
\end{tabular}


ically similar. As in the previous analysis, the main effects for prime task, relatedness, and SOA were significant at $p<.001\left[F(1,23)=39.9, M S_{\mathrm{e}}=55,952 ; F(1,23)=\right.$ $15.4, M S_{\mathrm{e}}=7,401$; and $F(1,23)=65.6, M S_{\mathrm{e}}=19,153$, respectively], as was the prime task $\times$ SOA interaction $\left[F(1,23)=6.8, M S_{\mathrm{e}}=13,155, p<.05\right]$. The source of the four-way interaction involving task order seems to be that, unlike the naming-first condition, this search-first analysis showed a three-way interaction of prime task $\times$ relatedness $\times$ SOA that approached significance $[F(1,23)=$ 3.8, $\left.M S_{\mathrm{e}}=5,518, p<.06\right]$. Further analyses showed significant effects $(p<.001)$ of both SOA and relatedness when the prime task was naming $[F(1,23)=68.5$, $M S_{\mathrm{e}}=4,934$ and $\left.F(1,23)=17.5, M S_{\mathrm{e}}=6,962\right]$, but no relatedness effects when the prime task was letter search $(p>.15)$. In the latter case, only SOA reached significance $\left[F(1,23)=36.8, M S_{\mathrm{e}}=27,374, p<.001\right]$.

An error analysis was also performed on the lexical decision data for Experiment 3, including the same five variables used in the RT analysis. A main effect of relatedness $\left[F(1,44)=20.7, M S_{\mathrm{e}}=.995502, p<.001\right]$ and the prime task $\times$ relatedness interaction $[F(1,44)=6.3$, $\left.M S_{\mathrm{e}}=.692472, p<.05\right]$ were the only factors to reach significance. This interaction reflects the usual pattern of larger priming effects with the naming task (6.8\% errors) than with the search task $(2.4 \%)$.

\section{Discussion}

The results of this experiment confirm some previous findings and conflict with others. As in Experiment 1, when RP was low, there was no significant priming in the search condition at either short or long SOAs. That is, we could find no evidence of a purely automatic spreading activation process that remained unaffected by the nature of the prime task. As in Experiment 2, priming under letter search task conditions was found when the salience of the semantic relationship was increased, as in the RP.80 condition. The nature of the prime task continued to have an effect in the RP. 80 condition; priming effects in the search conditions were significantly smaller than those in the naming conditions. Nevertheless, it is clear that focusing attention at the semantic level of analysis can serve to reinstate semantic priming.

Contrary to our expectations, we did not find significant priming in the RP. 20 condition for either short or long SOAs when the prime task was naming. This finding stands in contrast to the results of Experiment 2, in which a priming effect was found in the RP. 20 condition at a somewhat longer SOA $(1,700 \mathrm{msec})$. The main difference between these experiments was the presentation time of the prime word (1,000 msec for Experiment 2 vs. $140 \mathrm{msec}$ for Experiment 3) and the fact that the subjects made their responses to the prime word before the lexical decision response in Experiment 2, but after the target response in Experiment 3. Although there is no clearcut explanation for this difference in results, it seems plausible that in the third experiment the subjects held the prime word at a relatively "shallow" level of processing (e.g., a phonological code) until the response could be made; this, in combination with the low semantic salience of the RP. 20 condition, may have served to prevent the needed attentional resources from being allocated at the semantic level. In contrast, in the second experiment, the subjects made a naming response before the onset of the target word. Because it was not necessary to maintain the phonological code for the prime word, and due to the longer SOA, attentional resources may have been free for allocation at the "default" level of semantic analysis.

A second result that deserves comment is that an interaction between RP and SOA, previously reported by den Heyer et al. (1983), did not emerge under any of the conditions. Instead, the proportion factor had the same effect at SOAs of both 240 and $840 \mathrm{msec}$ and in both the naming and search conditions. SOAs of 75 and $1,000 \mathrm{msec}$ were used by den Heyer et al., so it is possible that either the difference in the short SOAs between the two experiments or the demands of prime processing in the present study could account for the difference in results. However, as mentioned previously, both de Groot (1984) and Snow and Neely (1987) also reported proportion effects at SOAs as short as $80 \mathrm{msec}$, when no response to the prime was required. Thus, the reason that we found an effect of proportion of related trials at short SOAs but den Heyer et al. did not, remains unclear.

Finally, this experiment marks the first of our studies in which task order has interacted significantly with prime task and relatedness; in this case, prime task $\times$ relatedness $\times$ SOA was marginally significant when the search task was completed first, but that interaction did not approach significance when the naming task occurred first. In previous experiments (Henik et al., 1983), as well as in the present Experiment 2, task order interactions with either relatedness or prime task were found, generally reflecting an attenuation of relatedness or prime task effects when the letter search task occurred second. In the present study, the task order interaction suggests a more complicated pattern, and one that is somewhat difficult to interpret. The RP factor, which clearly has an important effect on the size of the priming effect in general, did not contribute to this interaction; therefore, these results were collapsed across the RP. 80 and RP. 20 conditions. This interaction suggests that the effect of prime task on the priming effect can be modulated by task order; that is, the prime task effect was clearer when the letter search task was carried out first. When the search task was first, we basically replicated our previous finding that priming occurred in the naming but not in the search task condition, regardless of SOA. When the naming task was first, priming effects were found across all conditions. This pattern suggests that task order had an effect similar to that of proportion of related trials in this case. Both factors seemed to affect the salience of the relationship between the prime and target and thus modulate the prime task effect. 


\section{GENERAL DISCUSSION}

In the experiments reported here, we manipulated SOA and RP in order to determine the conditions under which semantic priming occurs when the prime is searched for a letter. Although there is some suggestion of priming in the error data in Experiment 1, the RT data from Experiments 1 and 3 suggest that under certain prime task conditions, priming is eliminated even at short SOAs. In Experiments 2 and 3 , a semantic priming effect was found under high-RP conditions, which suggests that making the semantic relationship between the prime and target salient can serve to compensate for the effects of the letter search task.

Despite the replication of prime task effects at short SOAs found in these experiments, we remain concerned about whether this paradigm truly allows us to evaluate processes at short SOAs, or whether the long RTs in those conditions produce SOAs that are functionally much longer than intended. We have been unable to resolve this problem in the context of the present paradigm. Recently, however, researchers using different types of paradigms have provided converging evidence that priming can be eliminated at very short SOAs. As described earlier, Snow and Neely (1987) manipulated the manner in which subjects attended to the prime word by varying the overall construction of the stimulus list and found that semantic priming was either reduced or eliminated under "shallow" processing conditions, even at SOAs of 80 and $200 \mathrm{msec}$.

In a series of experiments using a dual-task paradigm that was more similar to the present study, we also have found evidence of reduced semantic priming at short SOAs (Henik, Tzelgov, Osimani, \& Friedrich, 1991). Subjects were asked to detect the presence of a visual or auditory probe (an asterisk near the prime word or a tone) that was presented at the time of the prime word display. Primetarget SOAs were set at 240 and $840 \mathrm{msec}$. The subjects were asked to make lexical decision responses to the target, followed by the probe-detection response. Across several experiments, there was consistent evidence that semantic priming was reduced or eliminated when the subjects performed the probe task (with either visual or auditory probes), compared with a control condition requiring lexical decisions only. Of particular importance here is the fact that these effects were found for both short and long SOAs, and that the lexical decision RTs in the short-SOA condition were not unusually long.

Taken together, these results suggest that the manner in which the prime word is processed determines whether or not a priming effect is found, even at prime-target intervals that are thought to reflect the rapid automatic spreading activation process. This pattern in turn suggests that the early component of priming requires that some attentional resources be allocated at the semantic level. The letter search task, on the other hand, requires attention at a nonlexical level. When the SOA is short, it is less likely that there will be enough time to select or change attentional priorities. However, it is possible that the level of analysis required for the task can be preset if the relevant information is available prior to prime presentation. That is, if the features of the task to be performed on the next trial are known, the subject may allocate resources according to task priorities in advance. In the case of the letter search task, the letter level would be preset to draw whatever resources are needed.

The notion that attention can be unintentionally drawn is not a new suggestion in the literature. Kahneman (1973) argued that a process can draw attention according to its demands; he suggested that attention (i.e., effort) invested in a task is mainly determined by the intrinsic demands of the task and that voluntary control over effort is quite limited. Thus, even if some resources are required for spreading activation, it is possible that the process is still "automatic" in the sense that the resources may be allocated without the intention of the subject. The concept of automaticity has been defined in a number of ways (Hasher \& Zacks, 1979; Kahneman \& Treisman, 1984; Posner, 1978; Schneider, Dumais, \& Shiffrin, 1984). The general consensus has been that automatic processes are involuntary, they do not require mental resources, they can be executed without intention, and they cannot be shut off by intention. However, several reports have shown that the voluntary and capacity features of a process may be separable (Kahneman \& Chajczyk, 1983; Kahneman \& Henik, 1981; Paap \& Ogden, 1981; Regan, 1981; Zbrodoff \& Logan, 1986). Thus, the automatic nature of such a process may be defined by its capability to draw necessary resources according to its demands, without intentional allocation of those resources.

A point that deserves some attention is the small but nonsignificant advantage for the related trials found in quite a few experiments, even under letter search conditions (Henik et al., 1983; Hoffman \& MacMillan, 1985). In some cases the priming effect was completely eliminated, but in other cases there were small but nonsignificant differences in the expected direction. Such trends across experiments are somewhat dangerous to try to interpret, but it seems possible that activation is initiated under the letter search condition; however, it may be either too faint to measure or appear in the data of too few subjects to be recognized as a real effect. This pattern may also be reflected in error rates, as Hoffman and MacMillan have suggested, although the number of subjects contributing errors is usually small and the error rates are very low.

These small but nonsignificant trends are especially interesting given that the priming effect in the letter search task can be reinstated by increasing RP, as demonstrated in Experiments 2 and 3. These results, in turn, support the notion that it is the reduction in processing resources at the semantic level that is responsible for the elimination of the relatedness effect when the primes are searched for letters. In our previous account of prime task effects (Henik et al., 1983), we discussed two possible mechanisms that may be responsible for the observed prime task effects. One involved some active inhibitory processes and 
the other involved a decay of activation due to the engagement with the letter search task. Additional research has suggested that lack of priming is not a function of an inhibitory process, and that the lexical entry for the prime word is activated under letter search conditions even though this activation does not appear to spread to related concepts (Friedrich et al., 1991). We believe that the present results also provide some support for the second account. That is, it seems that in spite of the letter search task, some activation of the prime word's semantic representation does occur but that there is little or no spread of activation to related concepts. Activation naturally decays, as suggested by Collins and Loftus (1975), and it is possible that this decay occurs more rapidly unless some resources are available to maintain the activation level. The realignment of attention with these processes, by increasing the salience of the semantic relationship, may reinforce activation and give rise to a significant priming effect.

Note that this proposed account suggests that the effects of prime task and RP operate in parallel. For the letter search task, analysis must be focused at the letter level for prime processing, although some activation of the semantic level may occur in a high-RP condition. The letter analysis process appears to reduce the effectiveness of the RP activation relative to that found in the naming prime task, however. This may seem counterintuitive at first; one might expect that the beneficial effects of RP would be greater in the letter search task, in which there is a paucity of semantic activation. The latter prediction assumes that a fixed amount of resources is moved away from the semantic level in the letter search task and is reallocated when RP increases, and that the increase in salience will essentially nullify the attention demands of the letter search task. Instead, we suggest that prime task and RP affect the activation levels of the different types of representations at the same time. Increased RP may help maintain some activation at the semantic level, but resources are still required and are being drawn to the letter level during the search prime task. A prime task such as naming may, in fact, prove to be more sensitive to semantic factors because resources do not need to be divided between letter and lexical levels in the naming task.

The manner in which these processes work and interact is clearly complex and much has yet to be resolved. For example, how do competing sources of information, such as prime task and RP, interact or obscure one another? To the extent that we have succeeded in tapping into early processes in these experiments, the data suggest that these processes can be modulated by prime task demands. This is clearly not an all-or-nothing phenomenon, however, because the balance between activation of letter and semantic levels can be shifted by increasing semantic salience.

\section{REFERENCES}

BECKER, C. A. (1980). Semantic context effects in visual word recognition: An analysis of semantic strategies. Memory \& Cognition, $\mathbf{8}$, 493-512.

Besner, D., Smith, M. C., \& McLeod, C. M. (1990). Visual word recognition: A dissociation of lexical and semantic processing. Journal of Experimental Psychology: Learning, Memory, \& Cognition, 16, 862-869.

BrEZNITZ, S. (1971). Associative norms (Hebrew). Jerusalem: The Hebrew University.

Collins, A. M., \& Loftus, E. F. (1975). A spreading-activation theory of semantic processing. Psychological Review, 82, 407-428.

DagenbaCH, D., CARR, T. H., \& Wilhelmsen, A. (1989). Taskinduced strategies and near-threshold priming: Conscious effects on unconscious perception. Journal of Memory \& Language, 28, 412-443.

DE Groot, A. M. (1984). Primed lexical decisions: Combined effects of the proportion of related prime-target pairs and the stimulus-onset asynchrony of prime and target. Quarterly Journal of Experimental Psychology, 36A, 253-280.

den Heyer, K., Briand, K., \& Dannenbring, G. L. (1983). Strategic factors in a lexical-decision task: Evidence for automatic and attention-driven processes. Memory \& Cognition, 11, 374-381.

FisCHLER, I. (1977). Associative facilitation without expectancy in a lexical decision task. Joumal of Experimental Psychology: Human Perception \& Performance, 3, 18-26.

Friedrich, F. J., HeniK, A., \& Tzelgov, J. (1991). Automatic processes in lexical access and spreading activation. Joumal of Experimental Psychology: Human Perception \& Performance, 17, 792-806.

GreenberG, S. N., \& Vellutino, F. R. (1988). Evidence for processing of constituent single- and multiletter codes: Support for multilevel coding in word perception. Memory \& Cognition, 16, 54-63.

Hasher, L., \& ZaCKS, R. T. (1979). Automatic and effortful processes in memory. Journal of Experimental Psychology: General, 108, 356-388.

Henik, A. Friedrich, F. J., \& Kellogg, W. A. (1983). The dependence of semantic relatedness effects upon prime processing. $\mathrm{Mem}$ ory \& Cognition, 11, 366-373.

Henik, A., Tzelgov, J., Osimani, A., \& Friedrich, F.J. (1991). Shared and specific attentional mechanisms in spatial and semantic systems. Manuscript submitted for publication.

Hoffman, J. E., \& MacMillan, F. W. (1985). Is semantic priming automatic? In M. I. Posner \& O. S. M. Marin (Eds.), Attention and performance XI (pp. 585-599). Hillsdale, NJ: Erlbaum.

Johnston, W. A., \& DARK, V. J. (1982). In defense of intraperceptual theories of attention. Journal of Experimental Psychology: Human Perception \& Performance, 8, 407-421.

Johnston, W. A., \& DARK, V. J. (1985). Dissociable domains of selective processing. In M. I. Posner \& O. S. M. Marin (Eds.), Attention and performance XI (pp. 567-583). Hillsdale, NJ: Erlbaum.

Kahneman, D. (1973). Attention and effort. Englewood Cliffs, NJ: Prentice-Hall.

Kahneman, D., \& CHAJCZYK, D. (1983). Tests of the automaticity of reading: Dilution of Stroop effects by color-irrelevant stimuli. Journal of Experimental Psychology: Human Perception \& Performance, 9, 497-509.

Kahneman, D., \& Henik, A. (1981). Perceptual organization and attention. In M. Kubovy \& J. R. Pomerantz (Eds.), Perceptual organization (pp. 181-211). Hillsdale, NJ: Erlbaum.

Kahneman, D., \& Treisman, A. (1984). Changing views of attention and automaticity. In R. Parasuraman \& R. Davies (Eds.), Varieties of attention (pp. 29-61). New York: Academic Press.

Kahneman, D., Treisman, A., \& Burkell, J. (1983). The cost of visual filtering. Journal of Experimental Psychology: Human Perception \& Performance, 9, 510-522.

KAYE, D. B., \& Brown, S. W. (1985). Levels and speed of processing effects on word analysis. Memory \& Cognition, 13, 425-434. 
Koriat, A. (1981). Semantic facilitation in lexical decision as a function of prime-target association. Memory \& Cognition, 9, 587-598.

MARCEL A. (1983). Conscious and unconscious perception: Experiments on visual masking and word recognition. Cognitive Psychology, 15, 197-237.

McKoon, G., \& RatclifF, R. (1986). Automatic activation of episodic information in a semantic memory task. Journal of Experimental Psychology: Learning, Memory, \& Cognition, 12, 108-115.

MEyer, D. E., \& SChVANEVELDT, R. W. (1971). Facilitation in recognizing pairs of words: Evidence of a dependence between retrieval operations. Journal of Experimental Psychology, 90, 227-243.

Meyer, D. E., \& Schvaneveldt, R. W. (1976). Meaning, memory structure and mental processes. Science, 192, 23-27.

NeELy, J. H. (1977). Semantic priming and retrieval from lexical memory: Roles of inhibitionless spreading activation and limited-capacity attention. Journal of Experimental Psychology: General, 106, 226-254.

NeELY, J. H. (1991). Semantic priming effects in visual word recognition: A selective review of current findings and theories. In D. Besner \& G. Humphreys (Eds.), Basic processes in reading: Visual word recognition (pp. 264-336). Hillsdale, NJ: Erlbaum.

PAAP, K. R., OGDEN, W. G. (1981). Letter encoding is an obligatory but capacity-demanding operation. Journal of Experimental Psychology: Human Perception \& Performance, 7, 518-528.

PoSNer, M. I. (1978). Chronometric explorations of mind. Hillsdale, NJ: Erlbaum.

Posner, M. I., \& SNyder, C. R. R. (1975a). Attention and cognitive control. In R. L. Solso (Ed.), Information processing and cognition (pp. 55-85). Hillsdale, NJ: Erlbaum.

Posner, M. I., \& Snyder, C. R. R. (1975b). Facilitation and inhibition in the processing of signals. In P. M. A. Rabbitt (Ed.), Attention and performance $V$ (pp. 669-682). London: Academic Press.

REGAN, J. (1981). Automaticity and learning: Effects of familiarity on naming letters. Journal of Experimental Psychology: Human Perception \& Performance, 7, 180-195.

Schneider, W., Dumais, S. T., \& Shiffrin, R. M. (1984). Automatic and control processing and attention. In R. Parasuraman \& D. R. Davies (Eds.), Varieties of attention (pp. 1-27). New York: Academic Press.
Smith, M. C. (1979). Contextual facilitation in a letter search task depends on how the prime is processed. Journal of Experimental Psychology: Human Perception \& Performance, 5, 239-251.

Smith, M. C., Theodor, L., \& Franklin, P. E. (1983). The relationship between contextual facilitation and depth of processing. Journal of Experimental Psychology: Learning, Memory, \& Cognition, 9, 697-712.

SNow, N., \& NeELy, J. H. (1987, November). Reduction of semantic priming from inclusion of physically or nominally related prime-target pairs. Paper presented at the meeting of the Psychonomic Society, Seattle.

TwEEDY, J. R., \& LAPINSKI, R. H. (1981). Facilitation of word recognition: Evidence of strategic and automatic factors. Quarterly Journal of Experimental Psychology, 33A, 51-59.

Tweedy, J. R., Lapinski, R. H., \& Schvaneveldt, R. W. (1977). Semantic-context effects on word recognition: Influence of varying the proportion of items presented in an appropriate context. Memory \& Cognition, 5, 84-89.

ZBrodoff, N. J., \& LoGaN, G. (1986). On the autonomy of mental processes: A case study of arithmetic. Journal of Experimental Psychology: General, 115, 118-130.

\section{NOTE}

1. Kaye and Brown (1985) have reported a significant priming effect when the prime task is letter search, but not when it involves a case judgment. On the basis of these results and those of other task combinations, they suggest that prime task effects need to be understood in terms of the speed of processing of different types of codes. However, we find these data difficult to interpret because the typical pattern of significant priming when a lexical decision is performed on both the prime and target was not found for their adult subjects.

(Manuscript received July 27, 1989; revision accepted for publication July 19,1993 .) 